\title{
Development and characterization of highly polymorphic long TC repeat microsatellite markers for genetic analysis of peanut
}

\author{
Selma E Macedo 1,2, Márcio C Moretzsohn², Soraya C M Leal-Bertioli², Dione MT Alves ${ }^{1,2}$, Ediene G Gouvea ${ }^{1,2}$, \\ Vânia CR Azevedo ${ }^{2}$ and David J Bertioli ${ }^{1,3^{*}}$
}

\begin{abstract}
Background: Peanut (Arachis hypogaea L.) is a crop of economic and social importance, mainly in tropical areas, and developing countries. Its molecular breeding has been hindered by a shortage of polymorphic genetic markers due to a very narrow genetic base. Microsatellites (SSRs) are markers of choice in peanut because they are codominant, highly transferrable between species and easily applicable in the allotetraploid genome. In spite of substantial effort over the last few years by a number of research groups, the number of SSRs that are polymorphic for A. hypogaea is still limiting for routine application, creating the demand for the discovery of more markers polymorphic within cultivated germplasm.

Findings: A plasmid genomic library enriched for TC/AG repeats was constructed and 1401 clones sequenced. From the sequences obtained 146 primer pairs flanking mostly TC microsatellites were developed. The average number of repeat motifs amplified was 23. These 146 markers were characterized on 22 genotypes of cultivated peanut. In total 78 of the markers were polymorphic within cultivated germplasm. Most of those 78 markers were highly informative with an average of 5.4 alleles per locus being amplified. Average gene diversity index (GD) was 0.6 , and 66 markers showed a GD of more than 0.5. Genetic relationship analysis was performed and corroborated the current taxonomical classification of $A$. hypogaea subspecies and varieties.
\end{abstract}

Conclusions: The microsatellite markers described here are a useful resource for genetics and genomics in Arachis. In particular, the 66 markers that are highly polymorphic in cultivated peanut are a significant step towards routine genetic mapping and marker-assisted selection for the crop.

\section{Background}

Peanut (Arachis hypogaea L.) is an oil crop of great importance in the tropics: in Africa, its production is comparable to all other grain legumes put together, and in Asia it provides about the same number of calories as soya (FAO, 2009). It has a narrow genetic base due to its recent origin event of tetraploidization [1,2], and this has hindered the application of molecular breeding in this crop.

Microsatellites or simple sequence repeats (SSRs) are useful molecular markers, are abundant, highly dispersed through the genomes of eukaryotes, and locus

\footnotetext{
* Correspondence: davidbertioli@unb.br

'Institute of Biological Sciences, Campus Darcy Ribeiro, University of Brasilia, CEP 70.910-900 Brasília, DF, Brazil

Full list of author information is available at the end of the article
}

specific. In addition they are the ideal markers for genotyping allotetraploid species, such as peanut, since they are usually co-dominant and multi-allelic. They are considered suitable as tools for genetic diversity studies, genetic linkage mapping, and for use in plant breeding programs [3].

Over the past years several research groups have put considerable effort into developing SSR markers for the genus Arachis in general and cultivated peanut in particular. Now about 5,000 SSR markers have been published [4-21]. These markers have been mainly used for diversity studies of germplasm, and for genetic mapping $([10,11,22-28]$. However, in spite of the number of markers available, the very low polymorphism observed within cultivated germplasm requires large-scale marker screening for the identification of sufficient polymorphic

\section{Biomed Central}


markers even for low density genetic maps in populations derived from cultivated $\times$ cultivated crosses. For example, in spite of extensive marker screening, the published SSR-based maps of cultivated peanut have only 131, 135 and 175 SSR markers $[22,23,28]$. In a previous study, we observed that AG/TC microsatellites were more polymorphic than AC/TG ones and that for cultivated germplasm, the highest polymorphism was observed for microsatellites with 21-25 motif repetitions [10]. In this context, we isolated and characterized long repeat AG/ TC SSRs as an effort to develop markers with high polymorphism levels for cultivated peanut [10].

\section{Findings}

\section{Sequencing}

Sequences were obtained for 1401 cloned genomic fragments. Most fragments were sequenced in both forward and reverse orientations. Of these 1401 cloned fragments, 65 harbored sequences very similar to already published markers and so were excluded from further analysis ( $\geq 50 \%$ of sequence with BLAST detected similarity with E-value $\leq \mathrm{E}-40$ ). Of the remaining sequences, 193 harbored microsatellite repeats. As expected, most were TC/AG repeats. The 143 unique SSR sequences were deposited in GenBank (accession numbers JN887491 to JN887636).

\section{Design of flanking primer pairs}

Of the 193 selected sequences, 135 were appropriate for primer design. Some sequences contained multiple microsatellite repeats that could not be flanked by a single primer pair. Therefore, in total 146 primer pairs were designed. The microsatellites amplified were generally long, the average number of motif repeats being 23

\section{Polymorphism levels}

All 146 primer pairs amplified PCR products of the expected size. Of these, 85 were polymorphic within the tetraploid samples (including cultivated peanut, a synthetic allotetraploid and an accession of the tetraploid wild species, $A$. monticola (Table 1 ), and 78 were polymorphic within cultivated germplasm (Table 2).

The average number of alleles amplified per locus was 5.5 , values of Gene Diversity (GD) were between 0.080 and 0.885 , with an average of 0.614. Sixty-six markers were highly polymorphic with a GD of more than or equal to 0.5 .

Within cultivated peanut, markers with 21-25 motif repetitions were the most polymorphic (69\%), followed by markers that amplified more than 30 motif repetitions $(60 \%$, most of the markers being composite or imperfect) (Figure 1). The lowest polymorphism was observed with short microsatellites, between 6-10 motif repetitions

\section{Genic content}

Thirty-six of the 135 marker sequences encoded putative proteins that had significant BLAST similarities to known predicted proteins of Arabidopsis and/or legumes (E-value $<1^{\mathrm{e}-07}$, (Additional File 1: Table S1). Of the highly polymorphic markers (GD $\geq 0.5$ ), $23 \%$ showed a significant BLAST similarity. This compares to $35 \%$ of the markers with $G D<0.5$ that do not show significant BLAST similarity.

\section{Genetic relationships}

Genetic similarities were estimated by the band-sharing coefficient [29] in pairwise comparisons of the 24 genotypes (Table 1), using 78 microsatellite loci. Genetic similarity values ranged from $0.42-0.77$, considering the 22 A. hypogaea genotypes used. Therefore all the genotypes were differentiated. A dendrogram based on UPGMA was constructed for the 24 genotypes (Figure 2 ). Cluster analysis showed two main groups according to the subspecies. Within these groups, genotypes of the same botanical varieties tended to group together.

\section{Discussion}

In spite of the considerable effort made by several research groups to develop molecular markers for cultivated peanut, the number of polymorphic markers available for this important crop is still limiting. One of the main challenges in the construction of linkage maps using populations derived from cultivated $\times$ cultivated crosses is the need to screen thousands of markers to obtain sufficient markers even for the construction of low density maps.

In this study we focused on the class of microsatellites that was shown to be the most highly polymorphic for cultivated peanut in a previous study, long $\mathrm{TC}$ repeats [10] For this, sequences were obtained from an enriched genomic library. For processing the sequences, the Staden software was used together with a module for the detection of microsatellites. Starting from a relatively large dataset of unassembled sequences, it was possible to quickly eliminate sequences that were similar to previously described markers, and assemble a compact database of microsatellite containing sequences. Using a naming convention of plasmid clones, it was possible to correctly assemble microsatellite-containing reads even when the only overlap between forward and reverse sequences were microsatellite repeats. This was particularly important for obtaining complete sequences when the repeats were long. For design of primer pairs, the program used took into account the quality values of consensus bases. This was reflected in the $100 \%$ success rate of amplification of the primer pairs.

Markers with 21-25 motif repetitions were the most polymorphic, while markers with shorter repeats tended 
Table 1 Arachis genotypes included in this study.

\begin{tabular}{|c|c|c|}
\hline Genotype & Species/Subspecies/Variety & Origin \\
\hline CV. BR 1 & A. hypogaea subsp. fastigiata var. fastigiata & Embrapa Cotton, Brazil \\
\hline CV. IAC-Caiapó & A. hypogaea subsp. hypogaea var. hypogaea & IAC, Sao Paulo, Brazil \\
\hline CV. IAC Runner 886 & A. hypogaea subsp. hypogaea var. hypogaea & IAC, Sao Paulo, Brazil \\
\hline Cv. IAC-Tatu & A. hypogaea subsp. fastigiata var. fastigiata & IAC, Sao Paulo, Brazil \\
\hline CV. IAC-5024 & A. hypogaea subsp. hypogaea var. hypogaea & IAC, Sao Paulo, Brazil \\
\hline Mf210 & A. hypogaea subsp. fastigiata var. fastigiata & Misiones, Argentina \\
\hline Mf2352 & A. hypogaea subsp. fastigiata var. aequatoriana & Pichincha, Ecuador \\
\hline Mf2517 & A. hypogaea subsp. fastigiata var. peruviana & Guayas, Ecuador \\
\hline Mf2534 & A. hypogaea subsp. hypogaea var. hirsuta & Pichincha, Ecuador \\
\hline Mf2681 & A. hypogaea subsp. fastigiata var. vulgaris & Georgia, USA \\
\hline Mf3207 & A. hypogaea subsp. fastigiata var. vulgaris & Asunción, Paraguay \\
\hline Mf1625 & A. hypogaea subsp. fastigiata var. vulgaris & Minas Gerais, Brazil \\
\hline Mf3618 & A. hypogaea subsp. hypogaea var. hirsuta & La Libertad, Peru \\
\hline Mf2430 & A. hypogaea subsp. fastigiata var. peruviana & Loja, Ecuador \\
\hline Mf3764 & A. hypogaea subsp. fastigiata var. peruviana & Loreto, Peru \\
\hline Mf3892 & A. hypogaea subsp. fastigiata var. aequatoriana & Lima, Peru \\
\hline Mf3884 & A. hypogaea subsp. fastigiata var. aequatoriana & San Martín, Peru \\
\hline Mf3911 & A. hypogaea subsp. hypogaea var. hirsuta & La Libertad, Peru \\
\hline Mf574 & A. hypogaea subsp. hypogaea var. hypogaea & Santa Cruz, Bolivia \\
\hline Mf788 & A. hypogaea subsp. hypogaea var. hypogaea & Tarija, Bolivia \\
\hline Of106 & A. hypogaea subsp. hypogaea type Xingu & Xingu Indigenous Park, Brazil \\
\hline Of107 & A. hypogaea subsp. hypogaea type Xingu & Xingu Indigenous Park, Brazil \\
\hline V14165 & A. monticola & Jujuy, Argentina \\
\hline$(\mathrm{K} 30076 \mathrm{xV} 14167)^{4 x}$ & A. ipaënsis $\times$ A. duranensis & Embrapa Cenargen, Brazil \\
\hline
\end{tabular}

Genotypes of Arachis hypogaea, A. monticola, and a synthetic allotetraploid used for SSR marker validation and for genetic relationship analysis. Arachis hypogaea genotypes represent both subspecies (hypogaea and fastigiata) and the six botanical varieties (hypogaea, hirsuta, fastigiata, vulgaris, aequatoriana, and peruviana). $(\mathrm{K} 30076 \times \mathrm{V} 14167)^{4 \times}$ is a synthetic allotetraploid. IAC is Campinas Agronomic Institute

to be less polymorphic. This general tendency agrees with previous studies and reinforces the view that long (21-25 motif repetitions) or composite TC microsatellites are probably the most polymorphic marker class for cultivated peanut. A slightly higher proportion of markers that were not polymorphic or less informative $(G D<0.5)$ showed significant similarities to protein encoding regions, probably reflecting a tendency for non-coding regions to be more polymorphic than coding regions. Overall 78 of the markers were polymorphic for the cultivated accessions and 66 of these had GD value of 0.5 or above.

Cluster analysis showed two main groups separating the two subspecies of $A$. hypogaea. Some tendency of grouping of genotypes according to their botanical varieties was also evident. The main exceptions were three accessions, Mf2517, Mf2352, and Mf2534, which clustered with no apparent reason. The upper group contained the five hypogaea/hypogaea genotypes and two of the three hypogaea/hirsuta genotypes. Arachis monticola and the two genotypes collected in the Xingu
Indigenous Park also clustered in this group. The Xingu material has some morphological traits, especially in the pods, exceeding the previously variation described in cultivated peanut [30], but it seems to be closely related to hypogaea/hypogaea and hypogaea/hirsuta varieties. Our results also showed the great genetic similarity of the varieties fastigiata and vulgaris, which formed a subgroup, and peruviana and aequatoriana, which formed a separate subgroup. Some studies have shown that genotypes of the varieties peruviana and aequatoriana were more closely related to genotypes of the subspecies hypogaea than to the other two varieties (fastigiata and vulgaris) of subspecies fastigiata $[8,17,31,32]$. Our results, in contrast, corroborated the current taxonomical classification, despite the small number of genotypes included.

\section{Conclusion}

In this study 146 new microsatellite markers were developed for Arachis. All of these markers are new and useful tools for genetics and genomics in Arachis, but in 
Table 2 List of the $\mathbf{7 8}$ polymorphic markers.

\begin{tabular}{|c|c|c|c|}
\hline $\begin{array}{l}\text { Marker } \\
\text { name }\end{array}$ & $\begin{array}{l}\text { Major Allele } \\
\text { Frequency }\end{array}$ & $\begin{array}{l}\text { Allele } \\
\text { number }\end{array}$ & $\begin{array}{l}\text { Gene } \\
\text { Diversity }\end{array}$ \\
\hline TC13C03 & 0.4737 & 3 & 0.5873 \\
\hline TC13E05 & 0.4773 & 8 & 0.7118 \\
\hline TC14B08 & 0.5000 & 5 & 0.6621 \\
\hline TC14H09 & 0.9565 & 2 & 0.0832 \\
\hline TC15F12 & 0.3182 & 12 & 0.8388 \\
\hline TC16A10a & 0.6786 & 6 & 0.5102 \\
\hline TC16A10b & 0.3333 & 5 & 0.7222 \\
\hline TC19A02a & 0.6667 & 2 & 0.4444 \\
\hline TC19A02b & 0.5238 & 4 & 0.6270 \\
\hline TC19B07 & 0.2500 & 8 & 0.8472 \\
\hline TC19E01 & 0.6667 & 3 & 0.5000 \\
\hline TC20B05 & 0.4762 & 7 & 0.7086 \\
\hline TC20D05 & 0.4545 & 7 & 0.6374 \\
\hline TC20E08 & 0.4231 & 5 & 0.7278 \\
\hline TC21A09 & 0.5435 & 4 & 0.6011 \\
\hline TC21C03 & 0.5000 & 6 & 0.6791 \\
\hline TC21D06a & 0.9286 & 2 & 0.1327 \\
\hline TC21D06b & 0.3913 & 3 & 0.6578 \\
\hline TC21G01 & 0.2368 & 6 & 0.8075 \\
\hline TC22B07 & 0.9583 & 2 & 0.0799 \\
\hline TC22D09 & 0.8125 & 3 & 0.3116 \\
\hline TC22G05 & 0.4750 & 5 & 0.5700 \\
\hline $\mathrm{TC} 22 \mathrm{H} 12$ & 0.5217 & 6 & 0.6522 \\
\hline TC23B10 & 0.4565 & 5 & 0.6408 \\
\hline TC23C08a & 0.8158 & 3 & 0.3144 \\
\hline TC23C08b & 0.9348 & 3 & 0.1238 \\
\hline TC23D04 & 0.3043 & 6 & 0.7741 \\
\hline TC23E04a & 0.3750 & 6 & 0.7188 \\
\hline TC23E04b & 0.5000 & 4 & 0.5564 \\
\hline TC23F04 & 0.8696 & 4 & 0.2382 \\
\hline TC23F09 & 0.5000 & 3 & 0.5450 \\
\hline TC23H10 & 0.2273 & 10 & 0.8636 \\
\hline TC24A06 & 0.3214 & 7 & 0.7985 \\
\hline TC24B05 & 0.2000 & 12 & 0.8850 \\
\hline TC24C06a & 0.3182 & 10 & 0.8068 \\
\hline TC24D06b & 0.6042 & 5 & 0.5460 \\
\hline TC24D12 & 0.5500 & 3 & 0.5950 \\
\hline TC24E01 & 0.9583 & 2 & 0.0799 \\
\hline TC24G10 & 0.5000 & 5 & 0.6796 \\
\hline TC25B04 & 0.4000 & 7 & 0.7025 \\
\hline TC25F03 & 0.5833 & 5 & 0.5747 \\
\hline TC25G11 & 0.3478 & 7 & 0.7561 \\
\hline TC27H12 & 0.6042 & 5 & 0.5868 \\
\hline TC28A12 & 0.2917 & 8 & 0.8090 \\
\hline TC28B01 & 0.2381 & 8 & 0.8345 \\
\hline TC28B07 & 0.4750 & 8 & 0.7213 \\
\hline
\end{tabular}

Table $\mathbf{2}$ List of the $\mathbf{7 8}$ polymorphic markers. (Continued)

\begin{tabular}{|c|c|c|c|}
\hline TC28E09 & 0.8261 & 2 & 0.2873 \\
\hline TC29C07b & 0.3913 & 5 & 0.6909 \\
\hline TC29H08 & 0.5909 & 3 & 0.5165 \\
\hline TC30D04 & 0.5217 & 6 & 0.6682 \\
\hline TC31C09 & 0.5417 & 3 & 0.5799 \\
\hline TC31G11a & 0.4000 & 8 & 0.7663 \\
\hline TC31G11b & 0.3750 & 4 & 0.7049 \\
\hline TC31H02 & 0.3636 & 6 & 0.7479 \\
\hline TC31H03 & 0.6190 & 4 & 0.5488 \\
\hline TC31H06 & 0.4545 & 7 & 0.7293 \\
\hline TC34E12 & 0.4737 & 4 & 0.6482 \\
\hline TC35F05 & 0.3182 & 7 & 0.7934 \\
\hline TC36C02 & 0.5789 & 5 & 0.6039 \\
\hline TC36C03 & 0.2778 & 6 & 0.7778 \\
\hline TC38A07 & 0.5000 & 4 & 0.5663 \\
\hline TC38F01 & 0.4375 & 7 & 0.7144 \\
\hline TC38H09 & 0.2667 & 7 & 0.8267 \\
\hline TC39A10 & 0.4474 & 9 & 0.7382 \\
\hline ТC39B04 & 0.5000 & 4 & 0.6400 \\
\hline TC39C01 & 0.5238 & 6 & 0.6712 \\
\hline TC39E08 & 0.3750 & 9 & 0.7986 \\
\hline TC39F01 & 0.2353 & 8 & 0.8443 \\
\hline TC39F08 & 0.4762 & 7 & 0.7007 \\
\hline TC40D04 & 0.4667 & 5 & 0.7022 \\
\hline TC40E08 & 0.9565 & 2 & 0.0832 \\
\hline TC41A05 & 0.4706 & 6 & 0.6990 \\
\hline TC41A10 & 0.5238 & 8 & 0.6689 \\
\hline TC41A11b & 0.1875 & 10 & 0.8750 \\
\hline TC41C05 & 0.9583 & 2 & 0.0799 \\
\hline TC41C11 & 0.4773 & 6 & 0.6911 \\
\hline TC42A02 & 0.4583 & 3 & 0.6424 \\
\hline TC42A05 & 0.5000 & 7 & 0.6710 \\
\hline Mean & 0.5056 & 5.51 & 0.6144 \\
\hline
\end{tabular}

List of the 78 polymorphic markers as screened against 22 accessions of $A$. hypogaea. Major allele frequencies, allele number amplified per locus, and gene diversity indices are also shown

particular the set of 66 markers highly polymorphic for cultivated peanut are a significant step towards routine molecular breeding in this important crop.

\section{Methods}

\section{Plant material and DNA extraction}

For construction of an SSR-enriched genomic DNA library, the peanut genotype $A$. hypogaea subsp. fastigiata var. fastigiata cv. IAC-Tatu was used. For marker validation and genetic relationship analysis, the following panel was used: a set of 22 A. hypogaea genotypes representing all six botanical varieties, a synthetic 


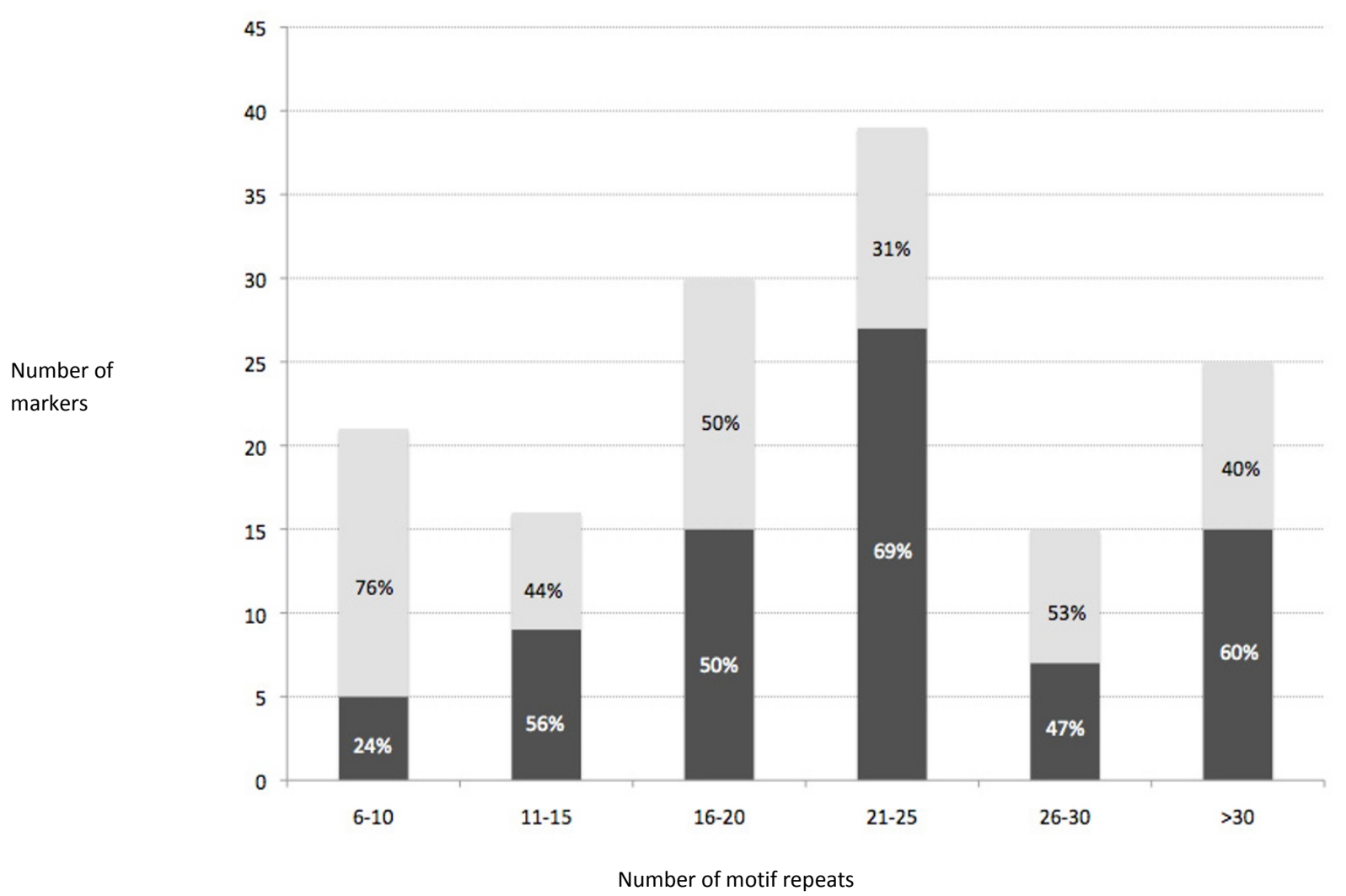

Figure 1 Frequency of markers detected per repeat size class. Frequency of markers developed in this study, polymorphic (dark grey), and monomorphic (light grey) per motif repeat number class. The percentage of polymorphic and monomorphic markers in each class is indicated on each bar of the graph.

allotetraploid (derived from a cross between A. ipaënsis and $A$. duranensis) and an accession of the tetraploid wild species, A. monticola (Table 1). Marker polymorphism was also assessed in parents of four mapping populations: A. duranensis K7988 × A.stenosperma V10309 [10,25], A. ipaënsis KG30076 × A. magna KG30097 [11], $A$. hypogaea subsp. hypogaea var. hypogaea cv. Runner IAC 886, and A. hypogaea subsp. fastigiata var. vulgaris cv. Fleur $11 \times$ a synthetic amphidiploid [24] (Additional file 1).

Total genomic DNA was isolated from young leaves using the CTAB-based protocol described by Grattapaglia and Sederoff [33] modified by the inclusion of an additional precipitation step with $1.2 \mathrm{M} \mathrm{NaCl}$. DNA quality and concentration were estimated on agarose gel electrophoresis and by spectrophotometry (Genesys 4 Spectronic, Unitech, USA).

\section{Construction of SSR-enriched library}

A genomic DNA library enriched for the dinucleotide repeats TC/AG was constructed as described by Moretzsohn [10]. About nine micrograms of DNA were digested with Sau3AI (Amersham Biosciences, UK) and electrophoresed in $0.8 \%$ low melting agarose gels to select fragments ranging from 200-600 bp. The selected fragments were purified from the agarose gels using phenol/chloroform, and ligated into Sau3AI specific adaptors (5'-cagcctagagccgaattcacc-3' and 5'-gatcggtgaaatcggctcaggctg-3'). The ligated fragments were hybridized to biotinylated (AG) 15 oligonucleotides and isolated using streptavidin-coated magnetic beads (Dynabeads Streptavidin, Dynal Biotech, Norway). The eluted fragments were amplified using one adaptor-specific primer, cloned into the pGEM-T Easy vector (Promega, WI, USA) and transformed into XL1-Blue E. coli cells with blue/white selection (Invitrogen, CA, USA). Plasmid DNAs of the positive clones were isolated by the alkaline lysis method. Sequencing reactions were performed with T7 and SP6 primers and the Big-Dye Terminator Cycle Sequencing Kit, version 3.1 (Applied Biosystems, CA, USA) using the ABI Prism 377 automated DNA sequencer.

\section{SSR marker development and validation}

Sequences were processed and assembled by using the Staden package [34] with the repeat sequence finding 


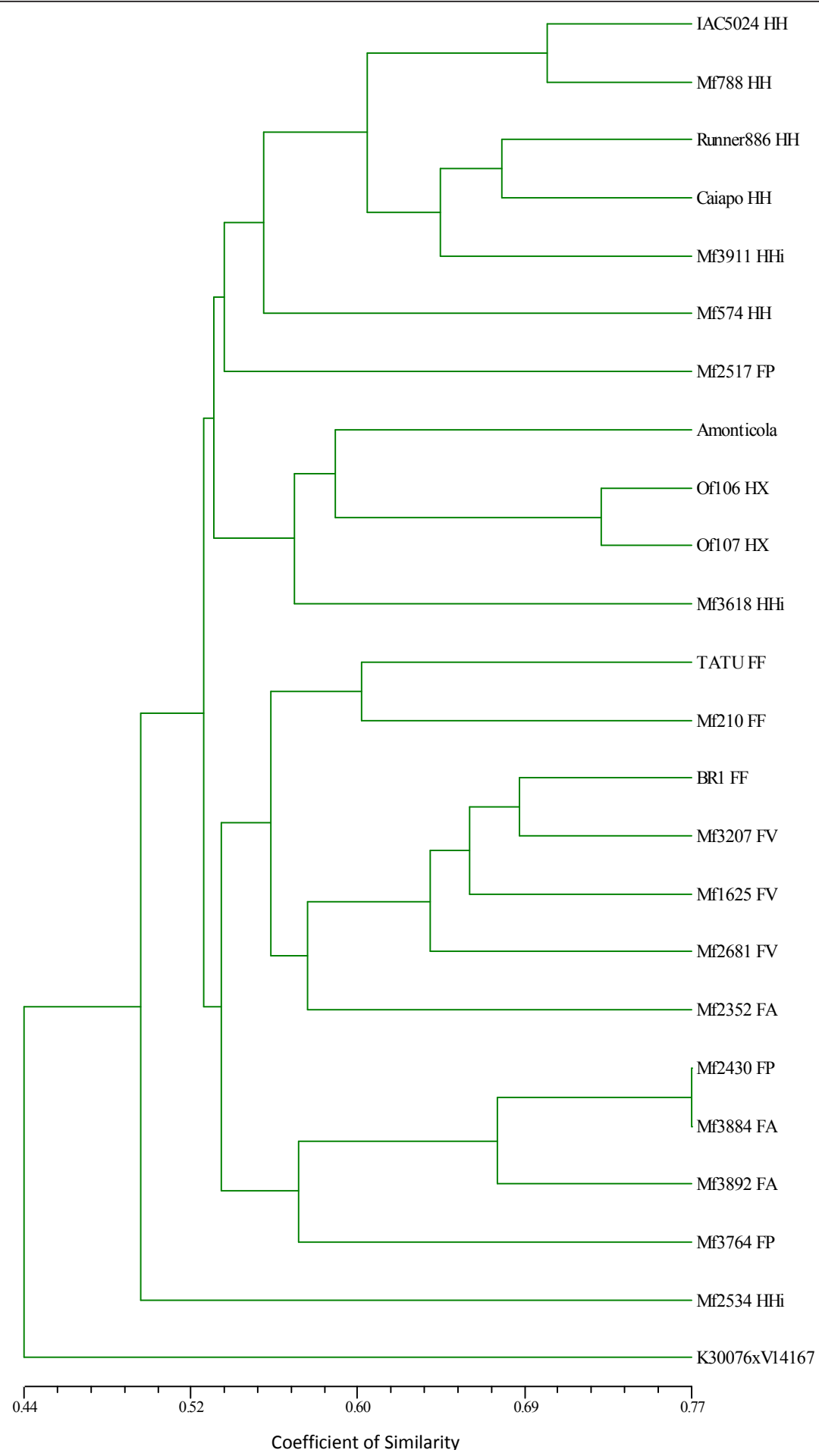

Figure 2 Dendrogram based on the band-sharing distances of 24 Arachis genotypes, generated by UPGMA. The letters, after each $A$. hypogaea accession number, refer to the subspecies, varieties, and type: FF-fastigiata/fastigiata; FV-fastigiata/vulgaris; FA-fastigiata/aequatoriana; FP-fastigiata/peruviana; HH-hypogaea/hypogaea; HHi-hypogaea/hirsuta; and HX-hypogaea Xingu type; an accession of A. monticola and a synthetic allotetraploid plant $(\mathrm{K} 30076 \times \mathrm{V} 14167)^{4 \times}$. Note, all accessions were distinguished, the highest point represented on the scale of similarity coefficient being 0.77 . 
module TROLL [35] and Primer3 for primer design [36], using a module developed by Martins et al. [37]. Sequences with more than ten motif repeats were chosen for primer design. Some sequences with BLASTX hits to genes of interest were also included in spite of having fewer than ten motif repeats. The parameters for primer design were: (1) primer size ranging from $18 \mathrm{bp}$ to $25 \mathrm{bp}$ with an optimal length of $20 \mathrm{bp}$; (2) primer $\mathrm{Tm}$ (melting temperature) ranging from $57^{\circ} \mathrm{C}$ to $63^{\circ} \mathrm{C}$ with an optimal temperature of $60^{\circ} \mathrm{C}$; and (3) GC content ranging from $40 \%-60 \%$. Default values were used for the other parameters.

PCR reactions contained $10 \mathrm{ng}$ of genomic DNA, $1 \mathrm{U}$ of Taq DNA polymerase (Amersham Biosciences, UK), $1 \times$ PCR buffer (200 mM Tris pH 8.4, $500 \mathrm{mM} \mathrm{KCl})$, 1.5-2.0 mM MgCl $2,200 \mu \mathrm{M}$ of each dNTP, and $0.4 \mu \mathrm{M}$ of each primer, in a final reaction volume of $10 \mu \mathrm{l}$. Amplifications were carried out in a PTC 100 thermocycler (MJ Research Inc., MA, USA). PCR conditions were: $96^{\circ} \mathrm{C}$ for $5 \mathrm{~min}$, followed by 30 cycles of $94^{\circ} \mathrm{C}$ for $1 \mathrm{~min}$, $48-62^{\circ} \mathrm{C}$ (annealing temperature depending on primer pair, see Additional file 1).

Total genomic DNA was isolated from young leaves using the CTAB-based protocol described by Grattapaglia and Sederoff [33] modified by the inclusion of an additional precipitation step with $1.2 \mathrm{M} \mathrm{NaCl}$. DNA quality and concentration were estimated on agarose gel electrophoresis and by spectrophotometry (Genesys 4 Spectronic, Unitech, USA).

\section{Construction of SSR-enriched library}

A genomic DNA library enriched for the dinucleotide repeats TC/AG was constructed as described by Moretzsohn [10]. About nine micrograms of DNA were digested with Sau3AI (Amersham Biosciences, UK) and electrophoresed in $0.8 \%$ low melting agarose gels to select fragments ranging from $200-600 \mathrm{bp}$. The selected fragments were purified from the agarose gels using phenol/chloroform, and ligated into Sau3AI specific adaptors (5'-cagcctagagccgaattcacc- 3 ' and 5' -gatcggtgaaatcggctcaggctg- $\left.3^{\prime}\right)$. The ligated fragments were hybridized to biotinylated (AG) ${ }_{15}$ oligonucleotides and isolated using streptavidin-coated magnetic beads (Dynabeads Streptavidin, Dynal Biotech, Norway). The eluted fragments were amplified using one adaptor-specific primer, cloned into the pGEM-T Easy vector (Promega, WI, USA) and transformed into XL1-Blue E. coli cells with blue/white selection (Invitrogen, CA, USA). Plasmid DNAs of the positive clones were isolated by the alkaline lysis method. Sequencing reactions were performed with T7 and SP6 primers and the Big-Dye Terminator Cycle Sequencing Kit, version 3.1 (Applied Biosystems, CA, USA) using the ABI Prism 377 automated DNA sequencer.

\section{SSR marker development and validation}

Sequences were processed and assembled by using the Staden package [34] with the repeat sequence finding module TROLL [35] and Primer3 for primer design [36], using a module developed by Martins et al. [37]. Sequences with more than ten motif repeats were chosen for primer design. Some sequences with BLASTX hits to genes of interest were also included in spite of having fewer than ten motif repeats. The parameters for primer design were: (1) primer size ranging from $18 \mathrm{bp}$ to $25 \mathrm{bp}$ with an optimal length of $20 \mathrm{bp}$; (2) primer $\mathrm{Tm}$ (melting temperature) ranging from $57^{\circ} \mathrm{C}$ to $63^{\circ} \mathrm{C}$ with an optimal temperature of $60^{\circ} \mathrm{C}$; and (3) GC content ranging from $40 \%-60 \%$. Default values were used for the other parameters.

PCR reactions contained $10 \mathrm{ng}$ of genomic DNA, $1 \mathrm{U}$ of Taq DNA polymerase (Amersham Biosciences, UK), $1 \times$ PCR buffer $(200 \mathrm{mM}$ Tris $\mathrm{pH} 8.4,500 \mathrm{mM} \mathrm{KCl})$, 1.5-2.0 mM MgCl $2,200 \mu \mathrm{M}$ of each dNTP, and $0.4 \mu \mathrm{M}$ of each primer, in a final reaction volume of $10 \mu \mathrm{l}$. Amplifications were carried out in a PTC 100 thermocycler (MJ Research Inc., MA, USA). PCR conditions were: $96^{\circ} \mathrm{C}$ for $5 \mathrm{~min}$, followed by 30 cycles of $94^{\circ} \mathrm{C}$ for $1 \mathrm{~min}$, $48-62^{\circ} \mathrm{C}$ (annealing temperature depending on primer pair, see Additional file 1).

Total genomic DNA was isolated from young leaves using the CTAB-based protocol described by Grattapaglia and Sederoff [33] modified by the inclusion of an additional precipitation step with $1.2 \mathrm{M} \mathrm{NaCl}$. DNA quality and concentration were estimated on agarose gel electrophoresis and by spectrophotometry (Genesys 4 Spectronic, Unitech, USA).

\section{Construction of SSR-enriched library}

A genomic DNA library enriched for the dinucleotide repeats TC/AG was constructed as described by Moretzsohn [10]. About nine micrograms of DNA were digested with Sau3AI (Amersham Biosciences, UK) and electrophoresed in $0.8 \%$ low melting agarose gels to select fragments ranging from 200-600 bp. The selected fragments were purified from the agarose gels using phenol/chloroform, and ligated into Sau3AI specific adaptors (5'-cagcctagagccgaattcacc-3' and 5'-gatcggtgaaatcggctcaggctg-3'). The ligated fragments were hybridized to biotinylated $(\mathrm{AG})_{15}$ oligonucleotides and isolated using streptavidin-coated magnetic beads (Dynabeads Streptavidin, Dynal Biotech, Norway). The eluted fragments were amplified using one adaptor-specific primer, cloned into the pGEM-T Easy vector (Promega, WI, USA) and transformed into XL1-Blue E. coli cells with blue/white selection (Invitrogen, CA, USA). Plasmid DNAs of the positive clones were isolated by the alkaline lysis method. Sequencing reactions were performed with T7 and SP6 primers and the Big-Dye 
Terminator Cycle Sequencing Kit, version 3.1 (Applied Biosystems, CA, USA) using the ABI Prism 377 automated DNA sequencer.

\section{SSR marker development and validation}

Sequences were processed and assembled by using the Staden package [34] with the repeat sequence finding module TROLL [35] and Primer3 for primer design [36], using a module developed by Martins et al. [37]. Sequences with more than ten motif repeats were chosen for primer design. Some sequences with BLASTX hits to genes of interest were also included in spite of having fewer than ten motif repeats. The parameters for primer design were: (1) primer size ranging from $18 \mathrm{bp}$ to $25 \mathrm{bp}$ with an optimal length of $20 \mathrm{bp}$; (2) primer $T m$ (melting temperature) ranging from $57^{\circ} \mathrm{C}$ to $63^{\circ} \mathrm{C}$ with an optimal temperature of $60^{\circ} \mathrm{C}$; and (3) $\mathrm{GC}$ content ranging from $40 \%-60 \%$. Default values were used for the other parameters.

PCR reactions contained 10 ng of genomic DNA, $1 \mathrm{U}$ of Taq DNA polymerase (Amersham Biosciences, UK), $1 \times$ PCR buffer (200 mM Tris pH 8.4, $500 \mathrm{mM} \mathrm{KCl})$, 1.5-2.0 mM $\mathrm{MgCl}_{2}, 200 \mu \mathrm{M}$ of each dNTP, and $0.4 \mu \mathrm{M}$ of each primer, in a final reaction volume of $10 \mu \mathrm{l}$. Amplifications were carried out in a PTC 100 thermocycler (MJ Research Inc., MA, USA). PCR conditions were: $96^{\circ} \mathrm{C}$ for $5 \mathrm{~min}$, followed by 30 cycles of $94^{\circ} \mathrm{C}$ for $1 \mathrm{~min}$, $48-62^{\circ} \mathrm{C}$ (annealing temperature depending on primer pair, see Additional file 1).

Total genomic DNA was isolated from young leaves using the CTAB-based protocol described by Grattapaglia and Sederoff [33] modified by the inclusion of an additional precipitation step with $1.2 \mathrm{M} \mathrm{NaCl}$. DNA quality and concentration were estimated on agarose gel electrophoresis and by spectrophotometry (Genesys 4 Spectronic, Unitech, USA).

\section{Construction of SSR-enriched library}

A genomic DNA library enriched for the dinucleotide repeats TC/AG was constructed as described by Moretzsohn [10]. About nine micrograms of DNA were digested with Sau3AI (Amersham Biosciences, UK) and electrophoresed in $0.8 \%$ low melting agarose gels to select fragments ranging from 200-600 bp. The selected fragments were purified from the agarose gels using phenol/chloroform, and ligated into Sau3AI specific adaptors (5'-cagcctagagccgaattcacc-3' and 5' -gatcggtgaaatcggctcaggctg-3'). The ligated fragments were hybridized to biotinylated $(A G)_{15}$ oligonucleotides and isolated using streptavidin-coated magnetic beads (Dynabeads Streptavidin, Dynal Biotech, Norway). The eluted fragments were amplified using one adaptor- specific primer, cloned into the pGEM-T Easy vector (Promega, WI, USA) and transformed into XL1-Blue E. coli cells with blue/white selection (Invitrogen, CA, USA). Plasmid DNAs of the positive clones were isolated by the alkaline lysis method. Sequencing reactions were performed with T7 and SP6 primers and the BigDye Terminator Cycle Sequencing Kit, version 3.1 (Applied Biosystems, CA, USA) using the ABI Prism 377 automated DNA sequencer.

\section{SSR marker development and validation}

Sequences were processed and assembled by using the Staden package [34] with the repeat sequence finding module TROLL [35] and Primer3 for primer design [36], using a module developed by Martins et al. [37]. Sequences with more than ten motif repeats were chosen for primer design. Some sequences with BLASTX hits to genes of interest were also included in spite of having fewer than ten motif repeats. The parameters for primer design were: (1) primer size ranging from $18 \mathrm{bp}$ to $25 \mathrm{bp}$ with an optimal length of $20 \mathrm{bp}$; (2) primer $\operatorname{Tm}$ (melting temperature) ranging from $57^{\circ} \mathrm{C}$ to $63^{\circ} \mathrm{C}$ with an optimal temperature of $60^{\circ} \mathrm{C}$; and (3) $\mathrm{GC}$ content ranging from $40 \%-60 \%$. Default values were used for the other parameters.

PCR reactions contained $10 \mathrm{ng}$ of genomic DNA, $1 \mathrm{U}$ of Taq DNA polymerase (Amersham Biosciences, UK), $1 \times$ PCR buffer $(200 \mathrm{mM}$ Tris pH 8.4, $500 \mathrm{mM} \mathrm{KCl})$, 1.5-2.0 $\mathrm{mM} \mathrm{MgCl}_{2}, 200 \mu \mathrm{M}$ of each dNTP, and $0.4 \mu \mathrm{M}$ of each primer, in a final reaction volume of $10 \mu \mathrm{l}$. Amplifications were carried out in a PTC 100 thermocycler (MJ Research Inc., MA, USA). PCR conditions were: $96^{\circ} \mathrm{C}$ for $5 \mathrm{~min}$, followed by 30 cycles of $94^{\circ} \mathrm{C}$ for $1 \mathrm{~min}$, $48-62^{\circ} \mathrm{C}$ (annealing temperature depending on primer pair, see Additional file 1) for $1 \mathrm{~min}, 72^{\circ} \mathrm{C}$ for $1 \mathrm{~min}$, with a final extension for $10 \mathrm{~min}$ at $72^{\circ} \mathrm{C}$. PCR products were separated by electrophoresis on denaturing polyacrylamide gels (6\% acrylamide:bisacrylamide 29:1, $5 \mathrm{M}$ urea in TBE pH 8.3), stained with silver nitrate [38].

\section{Data analyses}

Number of alleles per locus, the range of fragment length and gene diversity (GD) were estimated for the polymorphic primers, using the program "Power Marker 3.25" [39]. Pairwise genetic similarities were estimated from the allelic data using the band-sharing coefficient of Lynch [29]. The resulting diagonal matrix was then submitted to cluster analysis using UPGMA ("unweighted pair-group method analysis"). In order to verify the consistency of the built dendrogram, the cophenetic correlation - $r$ [40] was calculated. All these analyses were performed using the software NTSYS 2.21 [41]. 


\section{Additional material}

Additional file 1: Table S1. Marker homologies and information. The file provides information on all markers used in this work: marker name, primer sequence, SSR motif, GenBank number, PCR conditions, fragment length, sequence homologies and if the primers are polymorphic (P) or monomorphic (M) for parents of four mapping populations.

\section{Acknowledgements}

The authors would like to acknowledge CNPq for a Research fellowship for $D B$, and Student fellowships for DMTA and EGG, Generation Challenge Programme project TLI and host institutions. We also acknowledge GS, IG and $\mathrm{JV}$ for providing the accessions included.

\section{Author details}

'Institute of Biological Sciences, Campus Darcy Ribeiro, University of Brasilia, CEP 70.910-900 Brasília, DF, Brazil. Embrapa Genetic Resources and Biotechnology, PqEB W5 Norte Final, CP 02372, CEP 70.770-900 Brasília, DF, Brazil. ${ }^{3}$ Biotechnology and Genomic Sciences, Catholic University of Brasilia, SGAN 916 Avenida W5, CEP 70.790-160 Brasilia, DF, Brazil.

\section{Authors' contributions}

SEM participated in the experimental work, the identification of SSRs, primer design, and marker screening. EGG and DMTA participated in marker screening. DJB and MCM participated in the design and implementation of the study, supervision of the work and processing interpretation of the results. SCML-B participated in data analysis, microsatellite marker validation and drafted the manuscript. VCRA participated in the construction of SSRenriched library. All authors read and approved the final manuscript.

\section{Competing interests}

The authors declare that they have no competing interests.

Received: 25 October 2011 Accepted: 3 February 2012

Published: 3 February 2012

\section{References}

1. Halward TM, Stalker HT, Larue EA, Kochert G: Genetic variation detectable with molecular markers among unadapted germ-plasm resources of cultivated peanut and related wild species. Genome 1991, 34:1013-1020.

2. Kochert G, Halward T, Branch WD, Simpson CE: RFLP variability in peanut (Arachis hypogaea L.) cultivars and wild species. Theor Appl Genet 1991, 81(5):565-570.

3. Collard B, Jahufer M, Brouwer J, Pang E: An introduction to markers, quantitative trait loci (QTL) mapping and marker-assisted selection for crop improvement: The basic concepts. Euphytica 2005, 142(1):169-196.

4. He G, Meng R, Gao H, Guo B, Newman M, Pittman RN, Prakash CS: Simple sequence repeat markers for botanical varieties of cultivated peanut (Arachis hypogaea L.). Euphytica 2005, 142:131-136.

5. Wei X, Liu L, Cui S, Chen H, Zhang J: Development of EST-SSR markers in peanut (Arachis hypogaea L.). Frontiers of Agriculture in China 2011, 5(3):268-273.

6. Hopkins M, Casa A, Wang T, Mitchell S, Dean R, Kochert G, Kresovich S: Discovery and characterization of polymorphic simple sequence repeats (SSRS) in peanut. Crop Science 1999, 39:1243-1247.

7. He G, Meng R, Newman M, Gao G, Pittman RN, Prakash CS: Microsatellites as DNA markers in cultivated peanut (Arachis hypogaea L.). BMC Plant Biol 2003, 3:3.

8. Ferguson ME, Burow MD, Schulze SR, Bramel PJ, Paterson AH, Kresovich S, Mitchell S: Microsatellite identification and characterization in peanut ( $A$. hypogaea L.). Theor Appl Genet 2004, 108:1064-1070.

9. Moretzsohn MC, Hopkins MS, Mitchell SE, Kresovich S, Valls JFM, Ferreira ME: Genetic diversity of peanut (Arachis hypogaea L.) and its wild relatives based on the analysis of hypervariable regions of the genome. BMC Plant Biol 2004, 4:11.

10. Moretzsohn M, Leoi L, Proite K, Guimarães P, Leal-Bertioli S, Gimenes M, Martins W, Valls J, Grattapaglia D, Bertioli D: A microsatellite-based, gene- rich linkage map for the AA genome of Arachis (Fabaceae). Theor Appl Genet 2005, 111(6):1060-1071.

11. Moretzsohn MC, Barbosa AVG, Alves-Freitas DMT, Teixeira C, LealBertioli SCM, Guimaraes PM, Pereira RW, Lopes CR, Cavallari MM, Valls JFM, et al: A linkage map for the B-genome of Arachis (Fabaceae) and its synteny to the A-genome. BMC Plant Biol 2009, 9:40.

12. Gimenes M, Hoshino A, Barbosa A, Palmieri D, Lopes C: Characterization and transferability of microsatellite markers of the cultivated peanut (Arachis hypogaea). BMC Plant Biology 2007, 7(9), doi:10.1186/1471-2229-7-9.

13. Bravo JP, Hoshino AA, Angelici C, Lopes CR, Gimenes MA: Transferability and use of microsatellite markers for the genetic analysis of the germplasm of some Arachis section species of the genus Arachis. Genetics and Molecular Biology 2006, 29(3):516-524.

14. Proite K, Leal-Bertioli S, Bertioli D, Moretzsohn M, da Silva F, Martins N, Guimaraes P: ESTs from a wild Arachis species for gene discovery and marker development. BMC Plant Biol 2007, 7(1):7.

15. Methylation-filtered and shotgun genomic sequences for diploid and tetraploid peanut taxa. [http://www.ncbi.nlm.nih.gov/]

16. Wang $C T$, Yang XD, Chen D, Lin Yu SX, Liu GZ, Tang YY, Xu JZ: Isolation of simple sequence repeats from groundnut. Electronic Journal of Biotechnology 2007, 10:473-480.

17. Cuc LM, Mace ES, Crouch JH, Quang VD, Long TD, Varshney RK: Isolation and characterization of novel microsatellite markers and their application for diversity assessment in cultivated groundnut (Arachis hypogaea L.). BMC Plant Biol 2008, 8:55.

18. Liang X, Chen X, Hong Y, Liu H, Zhou G, Li S, Guo B: Utility of EST-derived SSR in cultivated peanut (Arachis hypogaea L.) and Arachis wild species. BMC Plant Biol 2009, 9(1):35.

19. Song GQ, Li MJ, Xiao H, Wang XJ, Tang RH, Xia H, Zhao CZ, Bi YP: EST sequencing and SSR marker development from cultivated peanut (Arachis hypogaea L.). Electronic Journal of Biotechnology 2010, 13:7-8.

20. Yuan M, Gong L, Meng R, Li S, Dang P, Guo B, He G: Development of trinucleotide (GGC)n SSR markers in peanut (Arachis hypogaea L.). Electronic Journal of Biotechnology 2010, 13:5-6.

21. Koilkonda P, Sato S, Tabata S, Shirasawa K, Hirakawa H, Sakai H, Sasamoto S, Watanabe A, Wada T, Kishida Y, et al: Large-scale development of expressed sequence tag-derived simple sequence repeat markers and diversity analysis in Arachis spp. Molecular Breeding 2011, online first doi:10.1007/s11032-011-9604-8.

22. Hong YB, Chen XP, Liang XQ, Liu HY, Zhou GY, Li SX, Wen SJ, Holbrook CC, Guo BZ: A SSR-based composite genetic linkage map for the cultivated peanut (Arachis hypogaea L.) genome. BMC Plant Biol 2010, 10:1-13.

23. Hong YB, Liang XQ, Chen XP, Liu HY, Zhou GY, Li SX, Wen SJ: Construction of Genetic Linkage Map Based on SSR Markers in Peanut (Arachis hypogaea L.). Agricultural Sciences in China 2008, 7(8):915-921.

24. Foncéka D, Hodo-Abalo T, Rivallan R, Faye I, Sall M, Ndoye O, Favero A, Bertioli DJ, Glaszmann J-C, Courtois B, et al: Genetic mapping of wild introgressions into cultivated peanut: a way toward enlarging the genetic basis of a recent allotetraploid. BMC Plant Biol 2009, 9(1):103.

25. Leal-Bertioli SCM, Jose ACVF, Alves-Freitas DMT, Moretzsohn MC Guimaraes PM, Nielen S, Vidigal BS, Pereira RW, Pike J, Favero AP, et al: Identification of candidate genome regions controlling disease resistance in Arachis. BMC Plant Biol 2009, 9(1):112.

26. Varshney RK, Mahendar T, Aruna R, Nigam SN, Neelima K, Vadez V, Hoisington DA: High level of natural variation in a groundnut (Arachis hypogaea L.) germplasm collection assayed by selected informative SSR markers. Plant Breeding 2009, 128(5):486-494.

27. Sarvamangala C, Gowda MVC: Varshney RK: Identification of quantitative trait loci for protein content, oil content and oil quality for groundnut (Arachis hypogaea L.). Field Crop Res 2011, 122(1):49-59.

28. Varshney RK, Bertioli DJ, Moretzsohn MC, Vadez V, Krishnamurty L, Aruna R, Nigam SN, Ravi K, He G, Knapp SJ, et al: The first SSR based genetic linkage map for cultivated groundnut (Arachis hypogaea L.). Theor Appl Genet 2009, 118:729-739.

29. Lynch M: The Similarity Index and DNA Fingerprinting. Mol Biol Evol 1990, 7:478-484.

30. Freitas F, Moretzsohn M, Valls J: Genetic variability of Brazilian Indian landraces of Arachis hypogaea L. Genet Mol Res 2007, 6:675-684.

31. He G, Prakash C: Evaluation of genetic relationships among botanical varieties of cultivated peanut (Arachis hypogaea L.) using AFLP markers. Genetic Resources and Crop Evolution 2007, 48:347-353. 
32. Raina SN, Rani V, Kojima T, Ogihara Y, Singh KP, Devarumath RM: RAPD and ISSR fingerprints as useful genetic markers for analysis of genetic diversity, varietal identification, and phylogenetic relationships in peanut (Arachis hypogaea) cultivars and wild species. Genome 2001, 44:763-772.

33. Grattapaglia D, Sederoff R: Genetic linkage maps of Eucalyptus grandis and Eucalyptus urophylla using a pseudo-testcross: mapping strategy and RAPD markers. Genetics 1994, 137:1121-1137.

34. Staden R: The Staden sequence analysis package. Mol Biotechnol 1996 5(3):233-241.

35. Castelo AT, Martins W, Gao GR: TROLL - Tandem Repeat Occurrence Locator. Bioinformatics 2002, 18(4):634-636.

36. Rozen S, Skaletsky H: Primer3 on the WWW for General Users and for Biologist Programmers. Bioinformatics Methods and Protocols: Methods in Molecular Biology 2000, 132(3):365-386.

37. Martins W, de Sousa D, Proite K, Guimaraes P, Moretzsohn M, Bertioli D: New softwares for automated microsatellite marker development. Nucleic Acids Res 2006, 34(4):e31.

38. Creste S, Yulmann-Neto A, Figueira A: Detection of Single Sequence Repeat polymorphisms in denaturing polyacrylamide sequencing gels by silver staining. Plant Molecular Biology Reporter 2001, 19:299-306.

39. Liu K, Muse S: PowerMarker: an integrated analysis environment for genetic marker analysis. Bioinformatics 2005, 21(9):2128-2129.

40. Mantel $\mathrm{N}$ : The detection of disease clustering and a generalized regression approach. Cancer Res 1967, 27:209-220.

41. NTSYSpc: numerical taxonomy system. ver. 2.21. [http://www. exetersoftware.com/cat/ntsyspc/ntsyspc.html].

doi:10.1186/1756-0500-5-86

Cite this article as: Macedo et al: Development and characterization of highly polymorphic long TC repeat microsatellite markers for genetic analysis of peanut. BMC Research Notes 2012 5:86.

\section{Submit your next manuscript to BioMed Central and take full advantage of:}

- Convenient online submission

- Thorough peer review

- No space constraints or color figure charges

- Immediate publication on acceptance

- Inclusion in PubMed, CAS, Scopus and Google Scholar

- Research which is freely available for redistribution

Submit your manuscript at www.biomedcentral.com/submit 